\title{
Decarbonisation of the economy through the introduction of innovative technologies into the energy sector
}

\author{
Serhii Voitko ${ }^{1}$, Olena Trofymenko, ${ }^{2, *}$, and Tetiana Pavlenco ${ }^{2}$ \\ ${ }^{1}$ National Technical University of Ukraine "Igor Sikorsky Kyiv Polytechnic Institute", Department of \\ International Economics, 37 Victory avenue, build. 1, 03056 Kyiv, Ukraine \\ ${ }^{2}$ National Technical University of Ukraine "Igor Sikorsky Kyiv Polytechnic Institute", Department of \\ Theoretical and Applied Economics, 37 Victory avenue, build. 1, 03056 Kyiv, Ukraine
}

\begin{abstract}
The article is devoted to topical issues of decarbonisation of the economy. The main purpose of the article is to study the relationship existing among key indicators of economic development, innovation in the energy sector and the amount of emissions, in particular, GDP per capita, Fossil CO2 per capita, Global Energy Innovation Index as a resulting indicator of the level of innovative technologies development in the energy sector as well as indicators of the development of renewable energy in different countries. The article also aims to identify ways of improving innovative development of the energy sector based on the study of measures taken by leading countries. The negative global trends in the direction of decarbonisation of the economy are found, for example, the growth rate of global investment in energy efficiency in 2019 compared to 2016 decreased by almost 6\%, and the growth rate of investment in renewables fell by $0.7 \%$. The main specific results of the analysis serve as a basis for establishing the ways of improving innovative development of the energy sector of the national economy with appropriate recommendations, taking into account successful world experience, which will accelerate the achievement of Sustainable Development Goals 7 and 12.
\end{abstract}

\section{Introduction}

Energy production is an industry that largely determines the level of socio-economic development of the country. Today, almost all leading countries in the world are developing a fundamentally new ideology of construction and operation of the energy sector to provide safe, reliable, cost-effective, and environmentally friendly energy supply to consumers. This ideology is based on the active informatization and intellectualization of energy facilities, which are based on innovation processes. The combustion of fossil fuels is one of the main sources of emissions that cause global warming, and so far, it meets about $80 \%$ of world energy needs.

\footnotetext{
* Corresponding author: o.o.trofymenko@gmail.com
} 
One of the main objectives in the development of the energy sector at the global level is the introduction of innovative energy technologies to increase energy efficiency and reduce the polluting negative impact on the environment.

Global decarbonisation, that is, the transition on a global scale to a low-carbon economy, is a response to global climate change caused by anthropogenic emissions of greenhouse gases into the atmosphere. The goal of decarbonisation is to reduce these emissions to slow down climate change and minimize their damage. Two of the seventeen Global Sustainable Development Goals by 2030, approved at the UN Summit on Sustainable Development, are Goal 7 «Affordable and Clean Energy» and Goal 12 «Responsible consumption and production». Achieving this goal by 2030 involves many tasks, including decarbonisation of the economy, intensifying R\&D activities in energy production, increasing the share of renewable energy in the global energy balance, the introduction of energy innovations.

\section{Literature Review}

Modern scientists [1] define an innovation as a new or improved product or process (or a combination thereof) that differs significantly from the unit's previous products or processes and that has been made available to potential users (product) or brought into use by the unit (process). H. Brooks [2] states that energy technologies should be understood not only as technologies of preliminary production and end-use of energy, special equipment and facilities but also software, practical skills, and knowledge necessary for its effective application. According to K. S. Gallagher et al. [3] energy-technology innovation is the set of processes that can reduce the economic, environmental, or political costs associated with energy supply and use. R. M. Margolis [4] defines energy technology innovation as a set of processes for improving energy technologies and equipment. Innovations in the energy sector are the result of R\&D activities based on the use of new ideas, which are the object of implementation in the field of production and management of the energy sector to obtain economic, social, environmental, and scientific-technical effect [5]. We agree with O.Tkach and V. Oleksyuk [6] that energy innovations are the result of the accumulation of new knowledge materialized in energy-saving and energy-generating technologies. A. Grubler and C. Wilson [7] regard an energy technology innovation system as an analytical framework applied to energy technologies that place innovation stages, processes, and drivers within the context of innovation systems described by the four dimensions of knowledge; actors and institutions; resources; technology adoption and use.

The researchers from the European Commission (EC) [8], IRENA [9], Aspen Institute [10], and Deloitte [11] devote some studies to the problem of decarbonisation of the economy. In 2018, the EC presented a long-term strategic concept for reducing greenhouse gas emissions by 2050. It contains: maximizing energy efficiency; increasing the use of renewable energy sources (RES) and electrification; transition to environmentally friendly transport; support of a circular economy; development of 'smart' grids and communications; expansion of bioenergy and natural carbon sequestration; absorption of other $\mathrm{CO} 2$ emissions through carbon capture and storage technologies [12]. The recommendations of the European Decarbonization Initiative include [8]: 1) the need for constant research and innovation activities on decarbonisation of all sectors of the economy; 2) the creation of large programs focused on the implementation of systemic transdisciplinary innovations, including the development of partnerships with industry to jointly address the most complex aspects of decarbonisation 3) the support for the initiatives of real-life management of the transition from typical fossil-fuel-based local economies to zero-carbon ones. Cunliff \& Hart [13] offer to calculate The Global Energy Innovation Index. 


\section{Methods}

Within the framework of this study, we formed two scientific hypotheses that: 1) the introduction of innovative technologies into the energy sector has a positive impact on decarbonisation of the economy; 2) the development of renewable energy in Ukraine, in contrast to the global indicator, depends on the political vector of development. To support these hypotheses, we conducted the necessary stages of the study, within which general scientific methods were used. The main methods were the system and complex analysis, the research of dynamics of indicators' values, the system generalization.

At the first stage, the leading countries in terms of introducing innovative technologies into the energy sector were identified and their positions within GDP per capita and Fossil $\mathrm{CO} 2$ per capita were analysed. Thus, to assess the level of development of innovative technologies in the energy sector, Global Energy Innovation Index [13] was chosen as a resulting indicator. It consists of three indices, each of which measures one of the functions of the innovation system, namely: Option Generation, Scale-Up and Social Legitimation. These three indices, in turn, are composed of 14 components that have different weighing coefficients. For instance, Option Generation includes such indicators as public investment in clean energy RD\&D, public investment in basic energy science, change on clean energy RD\&D, diversity of RD\&D by technology type. Scale-up comprises such indicators as climate change mitigation patent applications, clean energy demonstration funding, CCS demonstrations, adv. nuclear industry, high-impact clean-tech start-ups, EY renewable energy country attractiveness. The functional component of social legitimation includes the following indicators: effective carbon price, incl. fossil fuel subsidies, fuel taxes, percent clean RD\&D, international cooperation in clean energy RD\&D.

In turn, GDP per capita was chosen as one of the main indicators of economic efficiency and Fossil CO2 per capita - as an indicator of carbon dioxide emissions that result from burning fossil fuels and cement production; the indicators help to assess the level of decarbonisation. The data processed by us were graphically presented. The ratios between the values of the necessary indicators on the Cartesian plane were visualized. In addition, we used the method of additional information on the graphs of the third variable in the form of the area of a circle. The comparison and analysis of these indicators in selected countries made it possible to partially confirm the first hypothesis.

At the second stage of the study, 70 countries were analysed within such areas of innovative development of the energy sector as the introduction and development of renewable energy. For this analysis, the overall indicator Renewable Consumption was selected and compared with Fossil CO2 per capita and GDP per capita. This also confirmed the first hypothesis. Since renewable energy was identified as an important area of decarbonisation of the economy, the pace of dynamics of global investment in Renewables, World Energy efficiency (end-use), Renewables (end-use) and other end-use was analysed.

At the third stage of the study, the Renewable Consumption indicator was chosen in order to confirm the second hypothesis. As this indicator is one of the resulting indicators of renewable energy development, it was necessary to analyse its dynamics in Ukraine and the world from 1998 to 2019. The results of the analysis confirmed the second hypothesis.

\section{Results}

In order to compile a list of leading countries in terms of the introduction of innovative technologies in the energy sector, we analysed the ranking of countries according to the Global Energy Innovation Index National Contributions to the Global Clean Energy Innovation System from the organization ITIF [1]. The components of the indicators by 
functional components, in general, determine the main current trends in the development of innovation in energy production, because they include specific areas for investment.

The ITIF Global Energy Innovation Index [13] is calculated for 23 countries that make significant contributions to clean energy innovation. Such countries as Norway, Finland, Japan, the United States and France are among the top 5 in terms of overall rating and the highest indicators of innovation. One of the main indicators of the national economy efficiency is GDP growth. At the same time, reducing the energy intensity of GDP is one of the indicators of energy efficiency of the national economy. Thus, in order to ensure that, it is necessary to introduce innovative technologies into the energy sector. Obviously, this will have a positive impact on the environment in the direction of decarbonisation. Therefore, we graphically depicted 23 countries with the values of the Global Index of Energy Innovation (the diameter of the circle) in the coordinates of the indices Fossil CO2 per capita (tons of CO2 per capita) and GDP per capita. All the data are for 2019, because, in 2019, a study of the Global Index of Energy Innovation was conducted.

Fossil $\mathrm{CO} 2$ per capita is the carbon dioxide emissions that result from burning fossil fuels and cement production. This index also includes carbon dioxide formed during the consumption of solid, liquid and gaseous fuels and gas combustion. Therefore, with the introduction of alternative and innovative technologies for energy production, their number should decrease. The graph shows that those countries that use traditional fuels more have a higher level of Fossil CO2 per capita and a relatively low index of energy innovation, in particular, countries such as Saudi Arabia and the United Arab Emirates. It should also be noted that the greater the value of GDP, the much higher the rate of $\mathrm{CO} 2$ emissions, so it is important to compare these indicators of developed countries. Such a comparison will make it possible to establish opportunities to increase the ratio of GDP to $\mathrm{CO} 2$ emissions.

Figure 1 shows that the leading country in the implementation of energy innovations is Norway with an overall estimate of the index of 15.5, with GDP per capita of 75419.63 dollars and a relatively low Fossil CO2 per capita of 8.89 tonnes. Finland takes second place by an overall estimate of the index, as it has the value of 14.8, its GDP per capita amounts to 48782.8 dollars and Fossil CO2 per capita is 7.81 tons of emissions. Japan is in third place by an overall estimate of the index with a score of 13.7, with lower GDP of 40246.9 dollars and slightly higher Fossil CO2 per capita - 9.09 ton emissions.

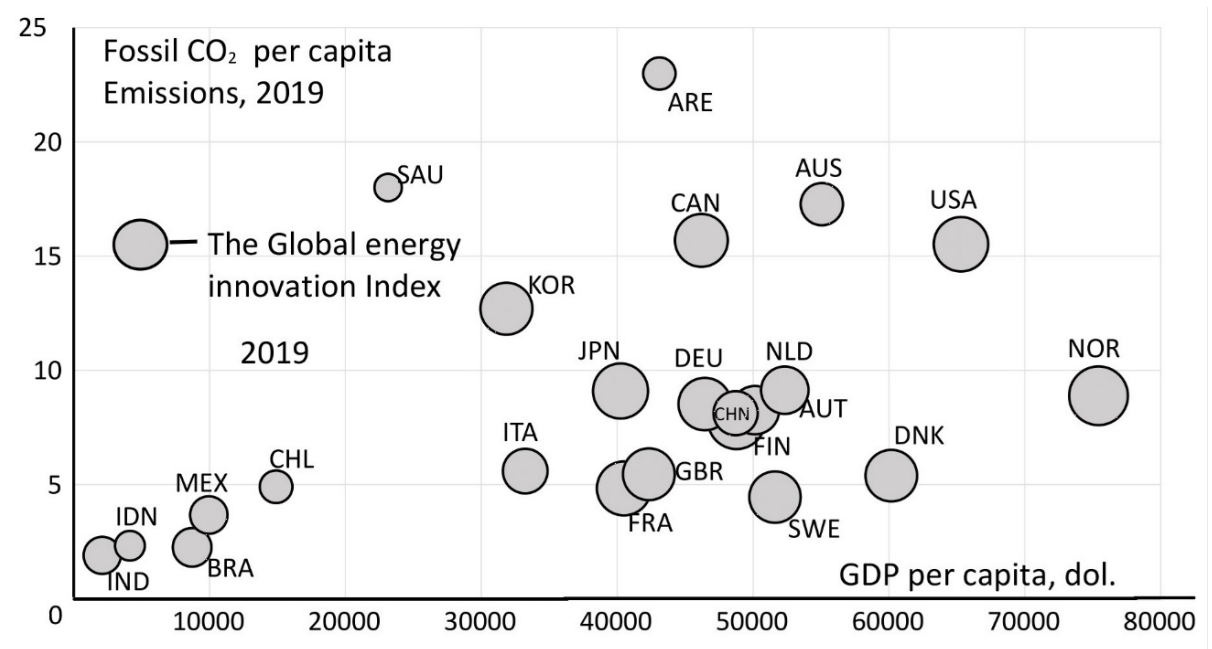

Fig 1. The ratio between GDP per capita and Fossil CO2 per capita (ton emission) in terms of the Global Energy Innovation Index [13-15] 
In general, based on the positions of the countries in these coordinates, one can say that there is no directly proportional relationship between GDP and Fossil CO2 per capita, and the Global Energy Innovation Index. It is observed only in some countries on the list, such as Norway, Denmark, the Netherlands, and China. However, it is obvious that high-tech countries have a high index of energy innovation, i.e. they invest in the development and dissemination of energy efficient technologies, for example Finland, France, Japan, Germany, Canada, the United Kingdom - with a GDP in the range of 40,000 to 55,000. In Finland, GDP per capita is $33 \%$ lower than in the United States, but in terms of energy innovation, Finland is $10 \%$ ahead of the United States. It is also worth noting that the US, Austria and Canada have relatively high $\mathrm{CO} 2$ emissions, although the US is ahead of Canada in terms of GDP, which indicates more environmentally friendly production of the USA. This means that technologically developed countries, regardless of their GDP, invest in energy efficiency and «clean» energy projects, which will reduce energy consumption and harmful emissions.

At the same time, countries such as Saudi Arabia, Chile, Mexico, Indonesia, India, and Brazil have relatively low GDP and commodity economies, and they implement much less energy innovation. For example, seven countries - China, Saudi Arabia, the United Arab Emirates, Indonesia, India, Mexico and South Korea - subsidized fossil fuel consumption in the amount of 171 billion dollars in 2018. They spent much more money on it than the selected 23 countries and the EU together spent on investment in R\&D in the field of clean energy (22.7 billion dollars in 2018), which, of course, is a negative factor in environmental development and ensuring innovative energy development.

Even though China has relatively small emissions of Fossil CO2 per capita, due to the large population of China, this country is the largest in terms of $\mathrm{CO} 2$ emissions in the world. As of 2019, CO2 emissions in China amounted to 11,535.2 million tons, which is $32.48 \%$ of global CO2 emissions. 5 countries - China, the United States, India, the Russian Federation, and Japan account for $62.47 \%$. The total amount of CO2 emissions in the world in 2019 amounted to $35,515.3$ million tons [14].

Table 1. Global investment in main decarbonization directions.

\begin{tabular}{|l|r|r|r|r|r|r|r|r|r|}
\hline Investment & $\mathbf{2 0 1 5}$ & $\mathbf{2 0 1 6}$ & $\mathbf{2 0 1 7}$ & $\mathbf{2 0 1 8}$ & $\mathbf{2 0 1 9}$ & \multicolumn{4}{|c|}{ Growth rate, \% } \\
\hline Renewables & 316,8 & 321,1 & 319,1 & 316,6 & 318,6 & 1,36 & $-0,62$ & $-0,78$ & 0,63 \\
\hline $\begin{array}{l}\text { World Energy } \\
\text { efficiency } \\
\text { (end-use), } \\
\text { billion USD }\end{array}$ & 239 & 264,9 & 250,9 & 251,6 & 249,4 & 10,8 & $-5,3$ & 0,3 & $-0,9$ \\
\hline $\begin{array}{l}\text { Renewables } \\
\text { (end-use) and } \\
\text { other end-use, } \\
\text { billion USD }\end{array}$ & 30,6 & 29,5 & 28,8 & 29,4 & 30,2 & $-3,6$ & $-2,4$ & 2,1 & 2,7 \\
\hline
\end{tabular}

Source: compiled and calculated by the authors based on [25]

An important direction of decarbonisation of the economy is the introduction and development of renewable energy, which belongs to the innovative areas of the energy sector [17]. In fig. 2, the diameter of the circle graphically determines the amount of renewable energy consumption in 70 countries, which are also depicted in the coordinates of Fossil CO2 per capita and GDP per capita. It is clear that the United States, China, Germany, Brazil, India, and the United Kingdom are the leaders in renewable energy consumption.

Table 1 shows the data and growth rates of global investment in renewables, world energy efficiency (end-use), renewables (end-use) and other end-use. The growth rate of 
global investment in energy efficiency technology in 2019 compared to 2016 significantly decreased. At the same time, global investment in renewables has been growing steadily. This indicates the priority of the development of renewable energy sources in the world.

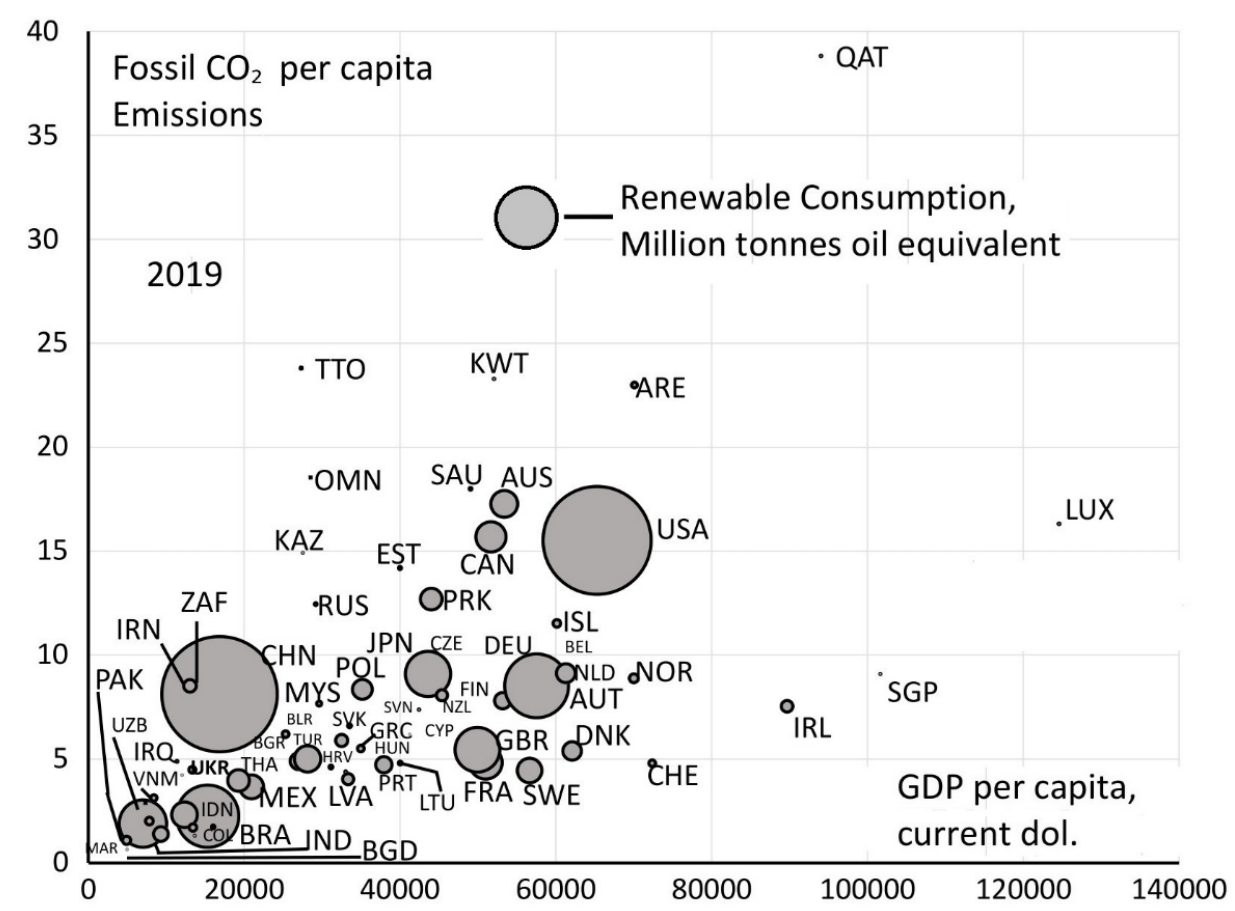

Fig 2. The proportion of GDP per capita to Fossil CO2 per capita (Emissions) in the context of Renewable Consumption [14-16].

It was also necessary to analyse the dynamics of renewable consumption in Ukraine and in the world since the growth of renewable energy capacities is one of the indicators of developing innovative technologies in the energy sector. Fig. 3 presents the dynamics of Renewable Consumption in Ukraine and in the world as a whole, which characterize the stages of the development of renewable energy consumption in the world in relation to Ukraine. Consumption based on renewable energy sources for the period from 1998 to 2019 was studied. It can be seen that by 2007 there was a gradual increase in the world consumption of renewable energy. From 2007 to 2009, there was a 44\% decline in renewable energy consumption in Ukraine but global consumption continued to grow. The decline in the use of renewable energy sources in Ukraine can be explained by an economic crisis of 2008-2009 in Ukraine resulting from the global crisis, as well as a political crisis of 2008-2009. From 2009 to 2011, there was a gradual increase in renewable energy consumption. From 2011 to 2014, renewable energy consumption in Ukraine increased by more than 7 times - from 0.05 million toe to 0.41 million toe, while in the world there was a steady rise in consumption - from 265.6 thousand toe up to 382.8 thousand toe. From 2014 to 2016, renewable energy consumption in Ukraine decreased again, which can be explained primarily by the political and economic situation in 2014. Moreover, in 2014, Ukraine experienced a political crisis, military aggression in the east, and the annexation of the Crimea by the Russian Federation.

These events had serious consequences such as inflation, a fall in real GDP by $6.8 \%$, which, of course, had a negative impact on the development of renewable energy capacity. 
From 2016 to 2019 , there was a fairly rapid increase in renewable energy consumption to 1.11 million toe. The provisions of the signed Association Agreement with the EU facilitated that process, as this agreement defines Ukraine's commitment to reforms, in particular, in the energy sector in favour of innovative environmental technologies and renewable energy.

In addition, the New Energy Strategy of Ukraine until 2035 was approved; in this document, renewable energy capacity was defined as one of the priorities. Thus, after analysing these data, we can conclude that global consumption of renewable energy is growing regardless of global crises, while the crisis in Ukraine has a negative impact on the development of renewable energy in Ukraine.

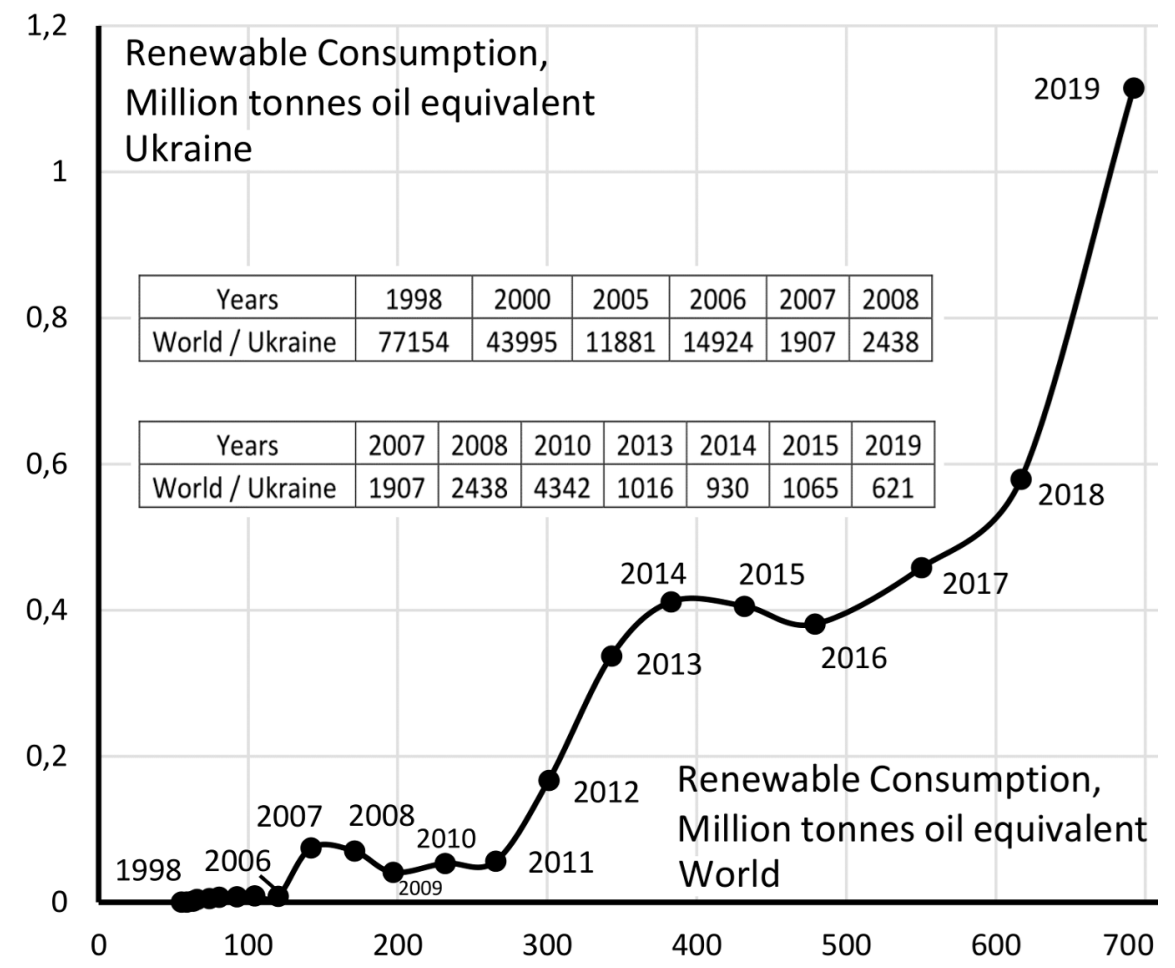

Fig. 3. The dynamics of Renewable Consumption in Ukraine and in the world for the period from 1998 to 2019 [16].

It is also reasonable to consider the main measures of the countries with a high global energy innovation index. The Norwegian government has developed a strategy for carbon capture and storage (CCS), which aims to identify measures to promote technology development and reduce CCS costs [18]. A feasibility report presented in 2016 showed that the implementation of a full-scale CCS network in Norway by 2022 is possible, moreover, with relatively low costs.

Another part of the CCS strategy is to further support CLIMIT, the Norwegian Centres for Environment-friendly Energy Research (FME) and international research activities. The Norwegian government investment in R\&D in the energy sector is a priority. CLIMIT is a national programme for research, development and demonstration of CCS technologies for both power plants and industry. The programme covers the entire chain - from basic research to innovative projects and demonstrations of CCS technology. 
In Finland, renewable energy sources account for about $40 \%$ of final energy consumption. The goal set by the National Energy and Climate Strategy by 2030 is to increase the use of renewable energy so that by 2020 its share in final energy consumption will increase to more than $50 \%$ [19].

As for Japan, its dependence on fossil fuels remains high. Japan's energy policy takes into account future changes in order to provide resources in line with the global structure of energy supply and demand, which is becoming increasingly volatile. The Government of Japan devises an action plan to implement the optimal portfolio of resources and to ensure stability and resource efficiency by diversifying key resources and reducing the risk of procurement of each resource through diversification of sources of supply, ensuring interest in joint projects and improving relations with suppliers [20].

According to the International Energy Agency, the United States is one of the world leaders in energy research, development and demonstration (RD\&D), with a large number of innovations in the energy sector. Federal government aims to finance and support energy innovation in the United States. This support is determined primarily by the Department of Energy, which also houses 17 national laboratories that are considered centres of research and development in the field of high-level energy. Currently, research activities of the Department of Energy focus on carbon capture, utilisation and storage, small modular nuclear reactors and battery storage. Nowadays variable renewable electricity generation is growing, electric vehicles are becoming more and more popular; however, the weather conditions are becoming extreme and the world is facing new cyber threats. Therefore, it is vital to carry out research into the ways of modernising and strengthening the power grid. The USA also takes part in international RD\&D in the field of energy. For instance, it is engaged in numerous IEA Technology Collaboration Programmes and it is a founding member of the Clean Energy Ministerial. Since the US is a global leader in clean energy technology and innovation, it is expected that these and other international projects of cooperation will be continuously supported [21].

The United Kingdom is putting effort into developing the energy sector in the direction of its decarbonisation. That is why the UK government has identified necessary measures in the areas of transport, buildings, industry, and heat. Thanks to the Carbon Price Support policy (CPS), it is possible to accelerate the transition to low-carbon energy-intensive consumption through appropriate price signals. Carbon prices are used in the field of electricity (however, if energy efficiency agreements are implemented, this industry is exempted according to the Carbon Price Floor (CPF) [22].

The main directions of the UK government's activities are aimed at formulating measures and defining policies in the following areas: the cost-efficiency of climate measures, reforms of the electricity market, maintaining energy security.

Germany has introduced a plan as part of its energy transition «Energiewende». It includes the transformation of the energy system into a more efficient one, which should be facilitated by renewable energy sources to a greater extent. Germany has adopted the Energy Concept document, which lays down the basic principles of Germany's energy policy until 2050. The main conceptual provisions of Germany's energy transition strategy are defined as follows: reduction of energy consumption in all sectors (using the principle «efficiency first»); use of renewable energy in the areas, where it is economically and environmentally sound; covering the balance of energy needs due to renewable energy [23].

Austria aims to ensure 100\% supply of renewable energy (national balance) by 2030 . This goal can be achieved if Austria increases its renewable electricity by about 22-27 terawatt-hours (TWh) by all technologies. Austria is already considered a world leader in renewable energy. In 2018, renewable energy sources in Austria accounted for $29 \%$ of the total primary energy supply. This indicator was the sixth largest among the IEA countries thanks to the largest shares of energy from bioenergy and hydropower. In 2018, renewable 
energy sources ensured slightly more than three quarters $(77 \%)$ of electricity production, which is the third largest share among IEA countries; hydropower was a major part of this production. Since 2017, the Austrian Research, Development and Innovation Strategy (RDI) has shifted the focus onto implementation-oriented projects and started to encourage scholars and scientists to be systematic in innovation processes. The RDI strategy is an essential part of the Austrian mission 2030 and it aims to achieve the goals of the national energy policy, ensuring their compliance with broader norms and priorities, not only for the energy sector [24].

The identified measures taken by the leading countries to stimulate innovative development of the energy sector should be recommended for consideration so that they can be further implemented in Ukraine.

\section{Conclusions}

The results of the study confirmed the hypotheses about the dependence of decarbonisation of the economy on the introduction of innovation into the energy sector and the impact of the political vector of development of Ukraine on the development of renewable energy. In general, negative factors in the ecology development and ensuring innovative development of the energy sector have been found. Since the introduction and development of renewable energy is one of the important directions of decarbonisation of the economy, the position of 70 countries in the coordinates of Fossil CO2 per capita and GDP per capita was reflected. We also analysed the growth rates of global investment in energy efficiency and renewables and other end-use. Additionally, we explored the dynamics of renewable energy consumption in Ukraine and in the world from 1998 to 2019, identified the possible causes of changes in consumption, and found that global consumption of renewable energy is increasing, regardless of the global crisis, while the crisis in Ukraine has a negative impact on the development of renewable energy. The main measures of the countries with a high index of global energy innovation and of leading countries with a developed energy policy were studied. These measures of the leading countries should be recommended for the implementation in Ukraine in order to achieve Sustainable Development Goals 7 and 12. The main specific results of the study consist in establishing the relationship existing among $\mathrm{CO} 2$ emissions reduction, the resulting indicators of innovation in the energy sector and the economy based on the analysis of them in different countries. The study also made it possible to identify areas for improving innovative development of the energy sector of the national economy, taking into account successful world experience.

This study was conducted in the context of cooperation with the Ministry of Economic Development, Trade and Agriculture of Ukraine for the project «Synergy of knowledge, experience and creativity for the future».

\section{References}

1. OECD/Eurostat (2018), Oslo Manual 2018: Guidelines for Collecting, Reporting and Using Data on Innovation, 4th Edition, The Measurement of Scientific, Technological and Innovation Activities, OECD Publishing, Paris/Eurostat, Luxembourg, https://doi.org/10.1787/9789264304604-en

2. Brooks, H. (1967). Applied Science and Technological Progress. Science, 156(3783), 1706-1712. https://doi.org/10.1126/science.156.3783.1706 
3. Gallagher, K. S., Holdren, J. P., \& Sagar, A. D. (2006). Energy-technology innovation. Annual Review of Environment and Resources, 31(1), 193-237. https://doi.org/10.1146/annurev.energy.30.050504.144321

4. Margolis, R. M. (2002). Understanding technological innovation in the energy sector: The case of photovoltaics. Princeton University.

5. Orumbaeva, S. R. (2012). Management of the development of the heat and power industry of the Republic of Kazakhstan: An innovative approach (doctoral dissertation). Al-Farabi Kazakh National University.

6. Tkach, O., \& Oleksyuk, V. (2016). Energy security of the country: conservation conditions and ways to achieve (innovative factor). Publishing house PE Korolchuk VF.

7. Grübler A., \& Wilson, C. (2014). Energy technology innovation learning from historical successes and failures. Cambridge University Press.

8. European Commission. (2018, December 3). Final Report of the High-Level Panel of the European Decarbonisation Pathways Initiative. https://ec.europa.eu/info/publications/final-report-high-level-panel-europeandecarbonisation-pathways-initiative en

9. IRENA International Renewable Energy Agency. (2018). Innovation priorities to transform the energy system. https://irena.org

10. Ballentine, R., \& Connaughton, J. (2021). Decarbonizing the Electricity Sector \& Beyond: Summary Report of the 2019 Winter Energy Roundtable. The Aspen Institute. https://www.aspeninstitute.org/publications/2019-winter-summary-report

11. Deloitte. (2020). The 2030 decarbonization challenge. https://www2.deloitte.com

12. Ministry of Energy and Environmental Protection (2020). The concept of «green» energy transition of Ukraine until 2050. Ukraine green dealhttps://mepr.gov.ua

13. Cunliff C., Hart D. M. (2019). The Global Energy Innovation Index: National Contributions to the Global Clean Energy Innovation System. https://itif.org/publications

14. EDGAR. (2019). Fossil CO2 and GHG emissions of all world countries, 2019 report. https://edgar.jrc.ec.europa.eu/overview.php?v=booklet 2019

15. Fu, H., Nguyen, M. C., \& Cull, B. (2021). World Bank Open Data. Data. https://data.worldbank.org

16. Statistical Review of World Energy: Energy economics: Home. bp global. (2021). https://www.bp.com/en/global/corporate/energy-economics/statistical-review-ofworld-energy.html

17. Trofymenko, O. (2020). Trends in the development of energy innovation in modern conditions. Economy and Society, (22). https://doi.org/10.32782/2524-0072/2020-22$\underline{90}$

18. The Government's carbon capture and storage strategy. Ministry of Petroleum and Energy. (2020). https://www.regjeringen.no/en/topics/energy/carbon-capture-andstorage/the-governments-carbon-capture-and-storage-strategy/id2353948

19. Ministry of Economic Affairs and Employment (2020). Renewable energy. https://tem.fi/en

20. Agency for Natural Resources and Energy (2019). Strategic Energy Plan. Strategic Energy Plan . https://www.enecho.meti.go.jp/en

21. IEA (2019). Energy Policies of IEA Countries: United States 2019 Review - Analysis. https://www.iea.org/reports/energy-policies-of-iea-countries-united-states-2019-review 
22. IEA (2019). Energy Policies of IEA Countries: United Kingdom 2019 Review Analysis. $\quad$ https://www.iea.org/reports/energy-policies-of-iea-countries-unitedkingdom-2019-review

23. IEA (2020). Germany 2020 - Analysis. https://www.iea.org/reports/germany-2020

24. IEA (2020). Austria 2020 - Analysis. https://www.iea.org/reports/austria-2020

25. IEA (2020). World Energy Investment 2020 - Analysis.

https://www.iea.org/reports/world-energy-investment-2020 